\title{
Optimization of Process Parameters of Stamping Forming of the Automotive Lower Floor Board
}

\author{
Guoying Ma and Binbing Huang \\ College of Mechanical and Electronic Engineering, Shandong University of Science and Technology, Qingdao 266590, China \\ Correspondence should be addressed to Binbing Huang; kinghuang1990@163.com
}

Received 19 May 2014; Revised 4 August 2014; Accepted 7 August 2014; Published 18 August 2014

Academic Editor: Ricardo Perera

Copyright (C) 2014 G. Ma and B. Huang. This is an open access article distributed under the Creative Commons Attribution License, which permits unrestricted use, distribution, and reproduction in any medium, provided the original work is properly cited.

There are many process parameters which have great effect on the forming quality of parts during automobile panel stamping forming process. This paper took automotive lower floor board as the research object; the forming process was analyzed by finite element simulation using Dynaform. The influences of four main process parameters including BHF (blank holder force), die corner radius, friction coefficient, and die clearance on the maximum thinning rate and the maximum thickening rate were researched based on orthogonal experiment. The results show that the influences of each value of various factors on the target are not identical. On this basis, the optimization of the four parameters was carried out, and the high quality product was obtained and the maximum thinning rate and maximum thickening rate were effectively controlled. The results also show that the simulation analysis provides the basis for the optimization of the forming process parameters, and it can greatly shorten the die manufacturing cycles, reduce the production costs, and improve the production efficiency.

\section{Introduction}

Automotive lower floor board has an important effect on the transportation process of vehicle; the performance of lower floor determines the stability and safety of the whole vehicle $[1,2]$. Automobile lower floor, engine cover, driving cab, and various special-shaped surface and the internal sheet parts of the body all belong to the automotive panels. Automobile panel is generally composed of the space free curved surface, and the production of it is a process of multistep and multiprocess due to its complex shape, small relative thickness, large size, and high surface quality requirements. The forming processes of automobile covering parts generally include drawing, trimming, stamping, shaping, flanging, and other processes, of which the stamping process is the most important step of all, and the results of the stamping are directly related to the product quality and subsequent process. In order to get qualified stamping automotive panel to meet customer requirements, multiple modifying and repeated debugging are required for stamping die, stamping process, technological parameters, and so forth, while "trial and error" method is used in the traditional way for repeated testing, which not only require a longer production cycle, but also require high production costs.

With the continuous development of numerical analysis technology, plastic forming theory, stamping technology, and computer technology, CAE (computer aided engineering) technology is gradually applied in stamping process and die design process for automotive panels [3, 4]; CAE related software are more and more widely used in panel die debugging process. The formability and possible defects of parts can be analyzed through the simulation, which provide the reliable basis for die debugging, so that it can reduce the die manufacturing problems, shorten the production cycle, save production costs, and offer more economic benefits for enterprises $[5,6]$.

In the stamping forming process of automotive panels, many process parameters have important influence on the quality of forming parts, and many scholars have done many studies in the optimization of process parameters [7-10]. In order to study the effects of several process parameters which have great influence on the forming quality of parts, which can be optimized, this paper adopts automotive lower floor board as the research object. Under the draw bead 


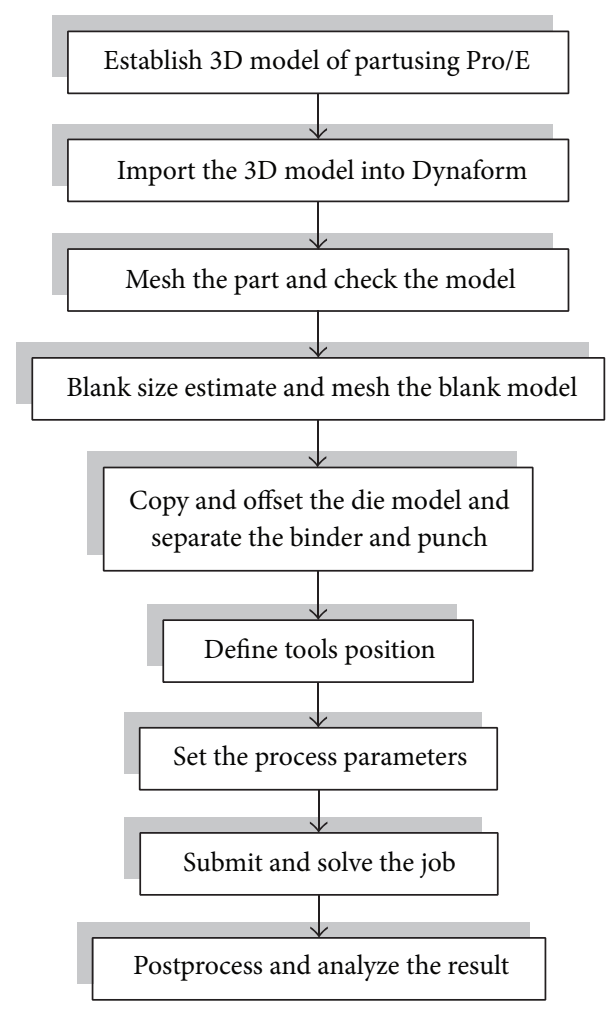

FIGURE 1: Flowchart of the process simulation.

distribution, the shape and parameters remain unchanged; use the orthogonal experiment and ETA (engineering technology associates)/Dynaform simulation software to analyze BHF (blank holder force), die corner radius, die clearance, and friction coefficient to study impact level of these four parameters with the results of maximum thinning rate and maximum thickening rate and optimize these parameters.

\section{Establishment of Simulation Analysis Model}

The simulation process of stamping forming mainly includes the establishment of 3D model and finite element models, defining the forming tools, setting the process parameters, and analyzing the results. The flowchart of the process simulation is shown in Figure 1.

\subsection{Establishment of 3D Model of Part Automotive Lower} Floor Board. According to the requirements of the analysis, draw three-dimensional model of automotive lower floor board parts by using Pro/E firstly. Analysis of the parts structure shows that the parts have large transverse size, small longitudinal size, large drawing depth, and complex shapes, so final shape should be finished; go through drawing $\rightarrow$ trimming $\rightarrow$ punching $\rightarrow$ shaping $\rightarrow$ flanging $\rightarrow$ lateral punching $\rightarrow$ trimming and other processes. Depending on the actual production experience, the cracking usually occurs at the lower portion of both ends of the parts; the flat ends and the mid plane may produce insufficient forming. On the basis of the defects the parts may arise; necessary process

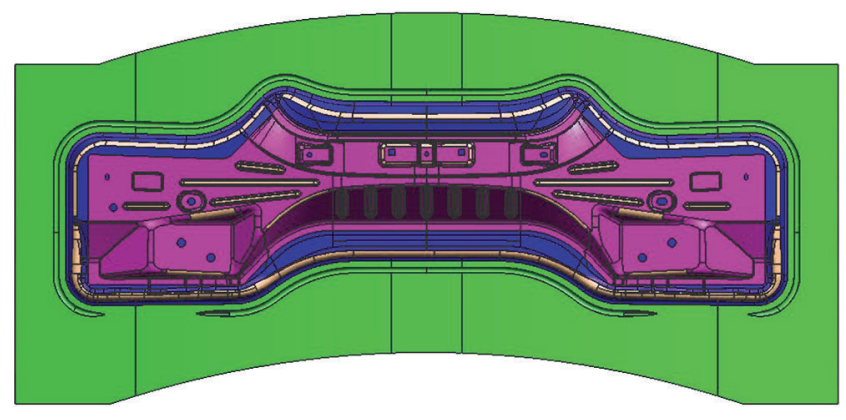

FIgure 2: Drawing die model (die).

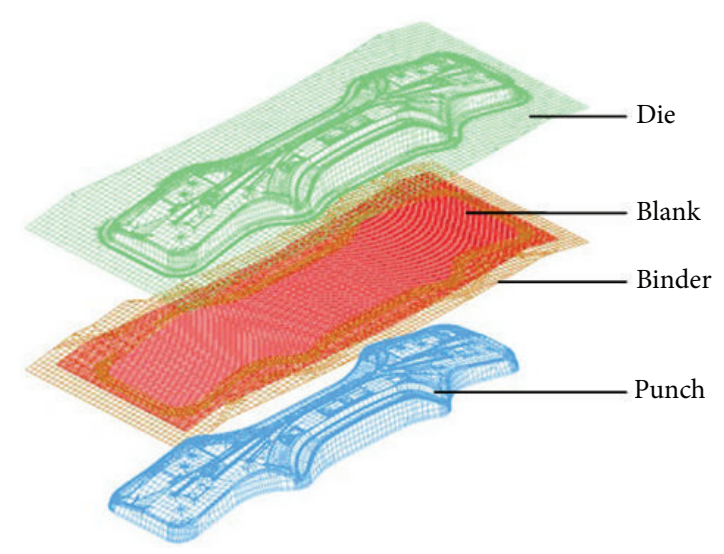

Figure 3: The FE model of automotive lower floor board.

supplement and binder surface shape design are required to reduce defects in the process of parts stamping. Drawing die model is shown in Figure 2; the part is defined as die and used as the forming tool during the simulation, and the model is saved as .igs format for subsequent finite element modeling.

2.2. Establishment of Finite Element Models. Dynaform software has a total of 16 element types; currently the most commonly used are Huhges-Liu (HL) shell element and Belytschko-Tsay (BT) shell element, and these two elements are constructed based on the Mindlin plate theory with the advantages of fast calculation speed and high simulation accuracy [11]. The default element type is Belytschko-Tsay shell element in Dynaform software, which is the most efficient element in explicit algorithm. In this paper, the die and sheet metal are meshed by using BT shell element. Comprehensively considering simulation accuracy and computation time, sheet mesh size $12 \mathrm{~mm}$ and adaptive grade 4 are accepted. And the finite element model of automotive lower floor board is shown in Figure 3. In order to ensure the overall forming quality of parts, draw bead distribution, shape, and parameters remain unchanged. The sheet metal use stamping steel WSS-M-1A365A12; the mechanical properties of the materials are given in Table 1 , and the plate thickness is $0.7 \mathrm{~mm}$. The plate is located on binder; the constitutive model of sheet material applied in this paper is the three parameters 
TABLE 1: Mechanical property parameters of WSS-M-1A365A12 steel sheet.

Mass density $/\left(\mathrm{kg} \cdot \mathrm{mm}^{-3}\right)$ Young's modulus/MPa Hardening rule Strength coefficient K/MPa Poisson ratio Lankford param $R$

\begin{tabular}{ccccccccc} 
& & & 0 & 45 & 90 \\
\hline $7.85 \times 10^{-3}$ & $2.1 \times 10^{5}$ & 0.225 & 586.8 & 0.3 & 1.35 & 1.15 & 1.65
\end{tabular}

Barlat-Lian thick anisotropic yield criterion [12]; the criterion is

$$
f=a\left|K_{1}+K_{2}\right|^{m}+a\left|K_{1}-K_{2}\right|^{m}+c\left|2 K_{2}\right|^{m}=2 \bar{\sigma}^{m}
$$

where $K_{1}=\left(\sigma_{x x}+h \sigma_{y y}\right) / 2, K_{2}=\sqrt{\left(\left(\sigma_{x x}-h \sigma_{y y}\right) / 2\right)^{2}+q^{2} \sigma_{x y}^{2}}$, $\bar{\sigma}$ is equivalent to yield stress, $\sigma_{x}$ is sheet stress along the rolling direction, $\sigma_{y}$ is sheet stress vertical to the rolling direction, $a, c, h$, and $q$ are the coefficient of material plastic anisotropy, and $m$ is Barlat-Lian index related to the crystal structure.

\section{Orthogonal Experiment Design}

Orthogonal experiment is a design method to study multiple factors level which is often used for the performance prediction of stamping forming of automotive panels [13-16]. During the process of automotive lower floor board stamping, the main process parameters affecting the forming performance include BHF, die corner radius, die clearance, and friction coefficient. For the above process parameters, orthogonal experiment factors were designed for the BHF (factor $A$ ), die corner radius (factor $B$ ), die clearance (factor $C$ ), and friction coefficient (factor $D$ ). The maximum thinning rate and maximum thickening rate are evaluation index, and the maximum thinning rate $\Delta$ is as follows:

$$
\Delta=\max \left(\frac{t_{0}-t_{i}}{t_{0}} \times 100 \%\right),
$$

where $t_{0}$ is the thickness of the sheet before drawing and $t_{i}$ is the thickness of unit $i$ of sheet metal after drawing.

Change $\left(t_{0}-t_{i}\right)$ in formula (2) into $\left(t_{i}-t_{0}\right)$ for maximum thickness ratio, and maximum thinning rate and maximum thickening rate of products should be as small as possible during the optimization in order to ensure product strength.

$\mathrm{BHF}$ is the force on the blank holder in drawing process; it can be used to solve the wrinkling problem in the process of drawing, and it can be calculated by the following formula:

$$
Q=F q
$$

where $F$ is the area of the pressure side $\left(\mathrm{mm}^{2}\right) ; q$ is for unit BHF (MPa), and its value is determined by experiment; unit BHF of different materials is selected according to Table 5.3 in [17]. From formula (3), the value of BHF was calculated to be about $500 \mathrm{kN}$, and the three levels of experiments were chosen for $400 \mathrm{kN}, 500 \mathrm{kN}$, and $600 \mathrm{kN}$.

There is virtually no effect of the punch speed on the forming performance [18]; we took the punch speed as $3000 \mathrm{~mm} / \mathrm{s}$ during all the simulation. The die corner radius
TABLE 2: Factors and levels of orthogonal experiment.

\begin{tabular}{|c|c|c|c|c|}
\hline \multirow[b]{2}{*}{ Number } & \multicolumn{4}{|c|}{ Factors } \\
\hline & $\begin{array}{c}A \\
\mathrm{BHF} / \mathrm{kN}\end{array}$ & $\begin{array}{c}B \\
\text { Die corner } \\
\text { radius } / \mathrm{mm}\end{array}$ & $\begin{array}{c}\text { C } \\
\text { Die } \\
\text { clearance } / \mathrm{mm}\end{array}$ & $\begin{array}{c}D \\
\text { Friction } \\
\text { coefficient }\end{array}$ \\
\hline 1 & 400 & 3 & $1.0 t$ & 0.10 \\
\hline 2 & 400 & 6 & $1.1 t$ & 0.12 \\
\hline 3 & 400 & 9 & $1.2 t$ & 0.14 \\
\hline 4 & 500 & 3 & $1.1 t$ & 0.14 \\
\hline 5 & 500 & 6 & $1.2 t$ & 0.10 \\
\hline 6 & 500 & 9 & $1.0 t$ & 0.12 \\
\hline 7 & 600 & 3 & $1.2 t$ & 0.12 \\
\hline 8 & 600 & 6 & $1.0 t$ & 0.14 \\
\hline 9 & 600 & 9 & $1.1 t$ & 0.10 \\
\hline
\end{tabular}

\begin{tabular}{lcccc}
\hline & \multicolumn{4}{c}{ Factors } \\
Level & $\begin{array}{c}A \\
\mathrm{BHF} / \mathrm{kN}\end{array}$ & $\begin{array}{c}B \\
\text { Die corner } \\
\text { radius/mm }\end{array}$ & $\begin{array}{c}C \\
\text { Die } \\
\text { clearance/mm }\end{array}$ & $\begin{array}{c}D \\
\text { Friction } \\
\text { coefficient }\end{array}$ \\
\hline 1 & 400 & 3 & $1.0 t$ & 0.10 \\
2 & 500 & 6 & $1.1 t$ & 0.12 \\
3 & 600 & 9 & $1.2 t$ & 0.14 \\
\hline
\end{tabular}

TABLE 3: Scheme of orthogonal experiment.

can affect the stamping process and we took $3 \mathrm{~mm}, 6 \mathrm{~mm}$, and $9 \mathrm{~mm}$ for the experiment. Die clearances were 1.0t, 1.1t, and $1.2 t$ with $t$ as sheet metal thickness. We set friction coefficient as $0.10,0.12$, and 0.14 for the experiment. The above factors were listed in Table 2; combination schemes of orthogonal experiment process parameters were designed by using orthogonal array $\mathrm{L}_{9}\left(3^{4}\right)$ as shown in Table 3.

\section{Results and Analysis of Orthogonal Experiment}

Due to the large number of experiment data, not all simulation results can be displayed; only the simulation results of process parameters scheme through the orthogonal experimental design corresponding to maximum thinning rate and maximum thickening rate were counted in Table 4.

From the simulation results in Table 4, it can be seen that the maximum thinning rate of most experiment parts 
TABLE 4: Thickness reduction and thinness reduction data obtained by orthogonal experiment.

\begin{tabular}{lcccccc}
\hline \multirow{2}{*}{ Number } & \multicolumn{2}{c}{ Factors } & \multicolumn{2}{c}{ Evaluation index } \\
& $A$ & $B$ & $C$ & $D$ & Maximum thinning rate/\% & 30.87 \\
1 & $A 1$ & $B 1$ & $C 1$ & $D 1$ & 29.14 & 6.27 \\
2 & $A 1$ & $B 2$ & $C 2$ & $D 2$ & 28.63 & 5.81 \\
3 & $A 1$ & $B 3$ & $C 3$ & $D 3$ & 36.31 & 5.87 \\
4 & $A 2$ & $B 1$ & $C 2$ & $D 3$ & 29.16 & 6.02 \\
5 & $A 2$ & $B 2$ & $C 3$ & $D 1$ & 29.07 & 5.53 \\
6 & $A 2$ & $B 3$ & $C 1$ & $D 2$ & 32.56 & 5.06 \\
7 & $A 3$ & $B 1$ & $C 3$ & $D 2$ & 35.87 & 4.98 \\
8 & $A 3$ & $B 2$ & $C 1$ & $D 3$ & 29.44 & 5.32 \\
9 & $A 3$ & $B 3$ & $C 2$ & $D 1$ & \\
\hline
\end{tabular}

TABLE 5: Range analysis of thickness reduction and thinness reduction data.

\begin{tabular}{|c|c|c|c|c|c|c|c|c|}
\hline \multirow{2}{*}{ Factors } & \multicolumn{4}{|c|}{ Maximum thinning rate $/ \%$} & \multicolumn{4}{|c|}{ Maximum thickening rate/\% } \\
\hline & $A$ & $B$ & C & $D$ & $A$ & $B$ & C & $D$ \\
\hline$K_{i 1}$ & 88.64 & 99.74 & 95.81 & 89.47 & 18.95 & 16.35 & 16.78 & 18.12 \\
\hline$K_{i 2}$ & 94.54 & 94.17 & 94.89 & 90.77 & 17.08 & 18.05 & 17.15 & 17.40 \\
\hline$K_{i 3}$ & 97.87 & 87.14 & 90.35 & 100.81 & 15.36 & 16.72 & 17.46 & 15.87 \\
\hline$k_{i 1}$ & 29.55 & 33.25 & 31.94 & 29.82 & 6.32 & 5.45 & 5.59 & 6.04 \\
\hline$k_{i 2}$ & 31.51 & 31.39 & 31.63 & 30.26 & 5.69 & 6.11 & 5.72 & 5.80 \\
\hline$k_{i 3}$ & 32.62 & 29.05 & 30.12 & 33.60 & 5.12 & 5.57 & 5.82 & 5.29 \\
\hline$R$ & 3.08 & 4.20 & 1.82 & 3.78 & 1.20 & 0.66 & 0.23 & 0.75 \\
\hline Optimal levels & $A 1$ & $B 3$ & $C 3$ & $D 1$ & $A 3$ & $B 1$ & $C 1$ & D3 \\
\hline Primary and secondary order & \multicolumn{4}{|c|}{$B>D>A>C$} & \multicolumn{4}{|c|}{$A>D>B>C$} \\
\hline Optimal combination & \multicolumn{4}{|c|}{$A 1 B 3 C 3 D 1$} & \multicolumn{4}{|c|}{$A 3 B 1 C 1 D 3$} \\
\hline
\end{tabular}

is below $30 \%$. In general, the reqkuirement of maximum thinning rate is not more than $30 \%$, while some parts of the automotive lower floor board thinning rate has exceeded the maximum value, so that the part has a very large risk of cracking; maximum thickening rate for all parts of the experiment program is between $4 \%$ and $7 \%$; there are small gaps among the results of each experiment scheme; the maximum thickening region is mainly in binder surface, which has a large risk of wrinkling. There are two common methods for solving wrinkling of the binder surface; one is to increase the $\mathrm{BHF}$, and one is to reduce the intensity of drawbeads, and the degree of solving wrinkling should be in accordance with customer requirements. The analysis results of the maximum thinning rate and maximum thickening rate are shown in Table 5, with $K_{i 1}, K_{i 2}$, and $K_{i 3}$, respectively, corresponding to the sum of 1,2 , and 3 level of $i(i=A, B, C, D)$ factors, $k_{i 1}, k_{i 2}$, and $k_{i 3}$, respectively, corresponding to the average value of 1,2 , and 3 level of $i(i=A, B, C, D)$ factors, and $R$ stands for range corresponding to each factor. The range in Table 5 represents the influence degree of various factors on the results. It can be seen that the range values of each factor are not equal, which indicates that the factors have different impacts on forming performance of automotive lower floor board. The relationship between the maximum thinning rate and experimental factors is shown in Figure 4, and the relationship between the maximum thickening rate and experimental factors is shown in Figure 5.

We can see clearly from the relationship shown in Figures 4 and 5 that the change trend of the maximum thinning rate and the maximum thickening is almost in the opposite condition with the experimental factors. The maximum thinning rate of automotive lower floor board increases along with the increases of $\mathrm{BHF}$; the maximum thickening rate decreases along with the increases of BHF. So the large $\mathrm{BHF}$ can avoid the wrinkle and also may lead to the risk of cracking. The influence of friction coefficient is the same as $\mathrm{BHF}$. The maximum thinning rate decreases along with the increases of die corner radius, and the maximum thickening rate increases first and decreases then along with the increases of die corner radius. The influence of die clearance is minor on these two evaluation indexes.

\section{Optimization Schemes and Simulation Results}

Due to some parts of automotive lower floor board higher thinning exists during stamping process; these areas would 

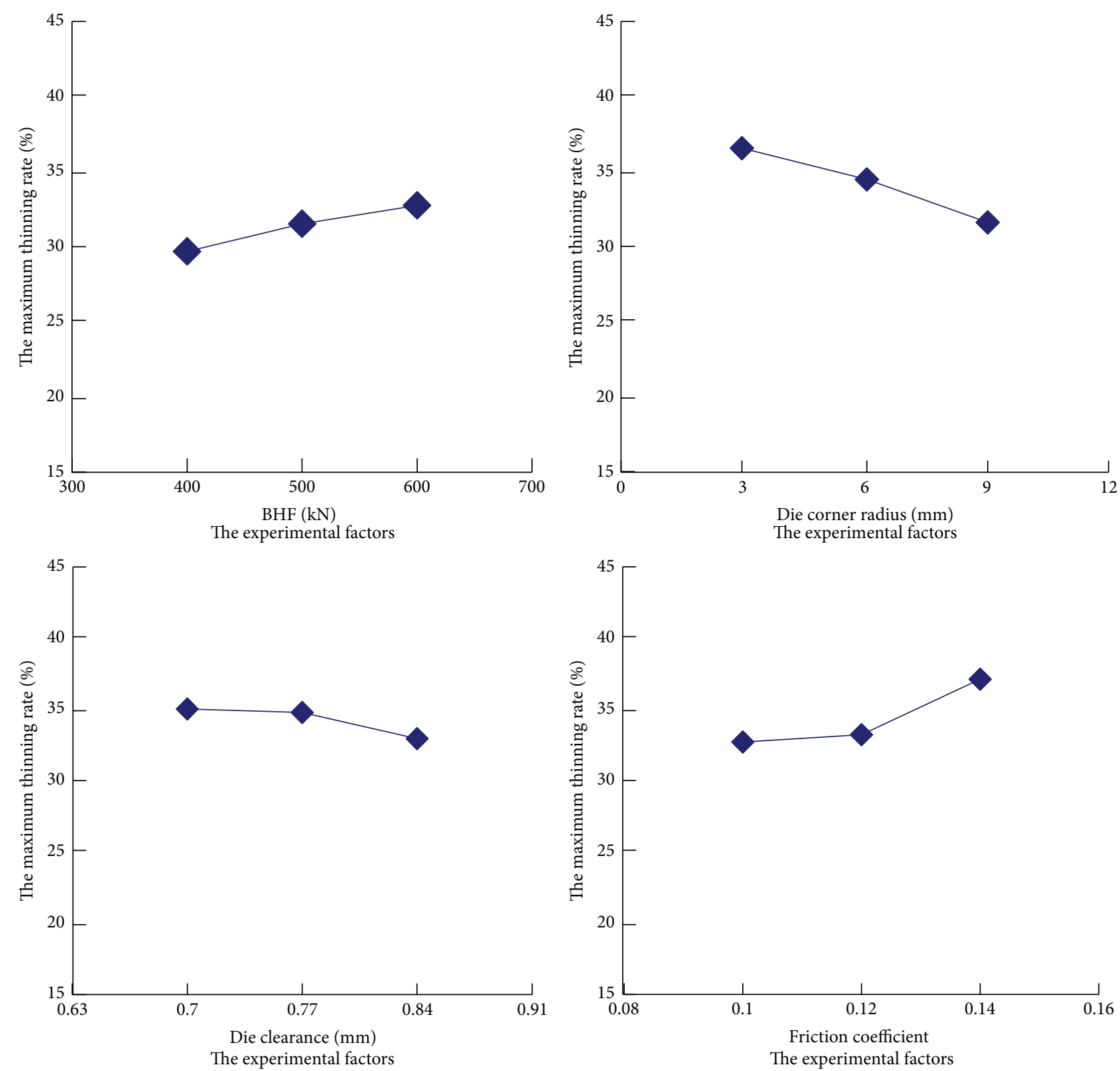

FIGURE 4: Relationship between the maximum thinning rate and experimental factors.

have a greater risk of cracking, and some parts of larger thickening would have a greater risk of wrinkling, double indexes optimization for process parameters were conducted by integrating these two reasons respectively. Single index of maximum thinning rate and maximum thickening rate corresponding to process parameters optimization results are given in Table 5. For the two factors, the maximum thinning rate and maximum thickening rate are the smaller the better, and the smaller the value is, the smaller the risk of cracking and wrinkling on the corresponding parts becomes; the defects of parts also reduce.

For the maximum thinning rate, die corner radius is the biggest influencing factor which determines the structure of die, friction coefficient is the secondary influencing factor which can be changed by adding the lubricant and changing the surface roughness, BHF can be modified by adjusting the parameters of mechanical presses, and die clearance can be adjusted by die repair. According to optimization scheme on the maximum thinning rate, the best optimization scheme is A1B3C3D1; with these parameters we take the simulation with ETA/Dynaform and the results of thickness distribution and forming limit diagram of A1B3C3D1 optimization scheme are, respectively, shown in Figures 6 and 7. After the optimization of process parameters, the maximum thinning rate of automotive lower floor board is $28.53 \%$, the maximum thickening rate is $6.34 \%$, the two rates are controlled in 

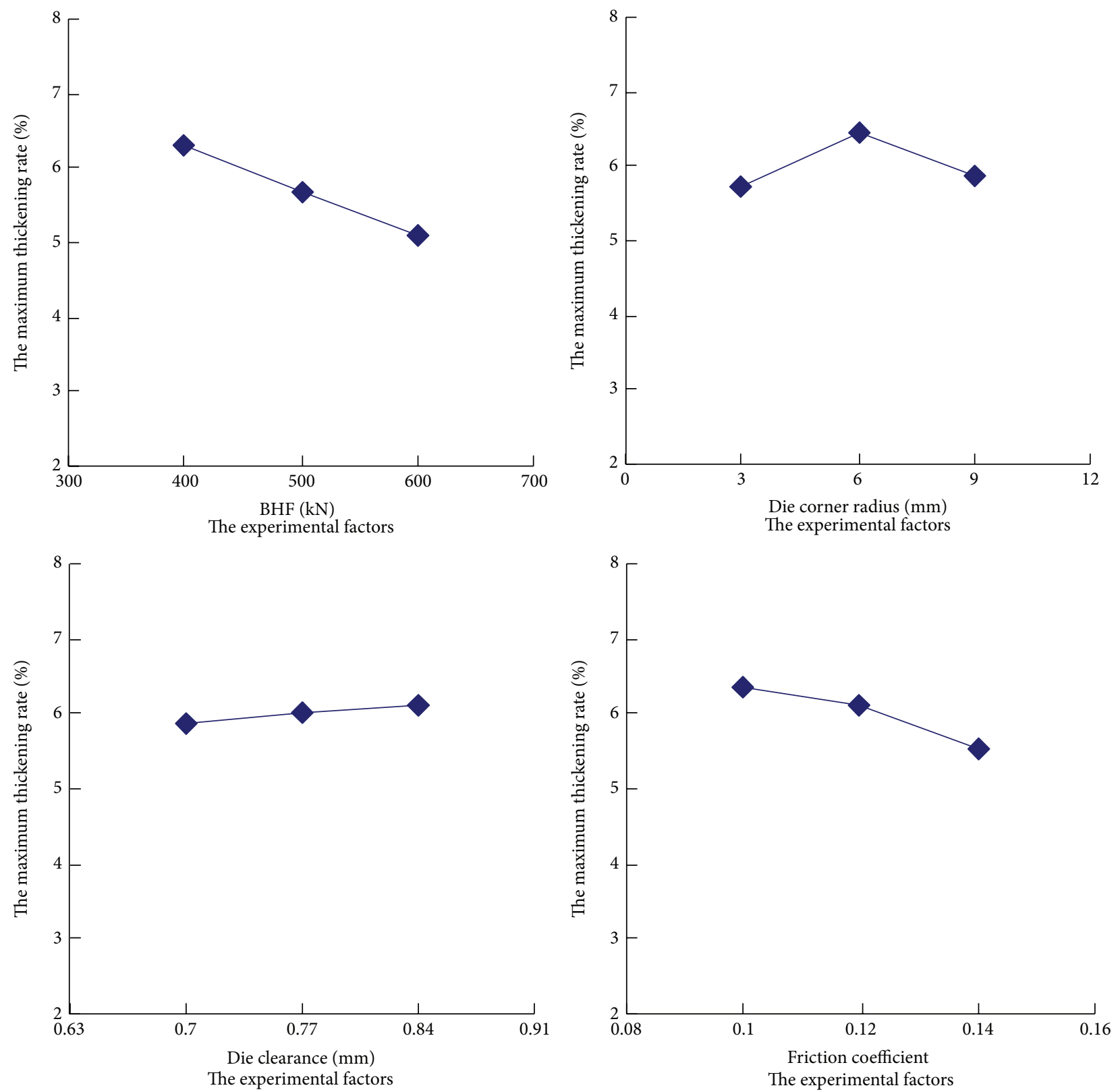

FIGURE 5: Relationship between the maximum thickening rate and experimental factors.

the required range, and the overall forming quality of parts is better without obvious defects.

For the maximum thickening rate, the biggest influencing factor is BHF and is followed by friction coefficient; die corner radius and die clearance have little effect on the maximum rate of thickening. The best optimization scheme for maximum thickening rate is $\mathrm{A} 3 \mathrm{~B} 1 \mathrm{ClD} 3$, and the simulation results of thickness distribution and forming limit diagram are, respectively, shown in Figures 8 and 9. In this case, the maximum thinning rate of automotive lower floor board is $40.10 \%$; the maximum thickening rate is $4.71 \%$. Obviously, the maximum thinning rate exceeds the forming limit and the automotive lower floor board will be cracked.
According to the orthogonal experiment and simulation by Dynaform, we chose the friction coefficient with 0.10, BHF with $400 \mathrm{kN}$, die clearance with $0.84 \mathrm{~mm}$, and die corner radius with $9 \mathrm{~mm}$ to take the actual production of automotive lower floor board for experiment. The stamping forming part is shown in Figure 10; we can find the lubricant on the surface of automotive lower floor board, which is used to reduce the friction coefficient of the parts to avoid the risk of cracking. The wrinkle only occurs in the outer plate where it will be cut off in the next process. The final product part is shown in Figure 11. We can find that the automotive lower floor board is in high quality without any defects. 


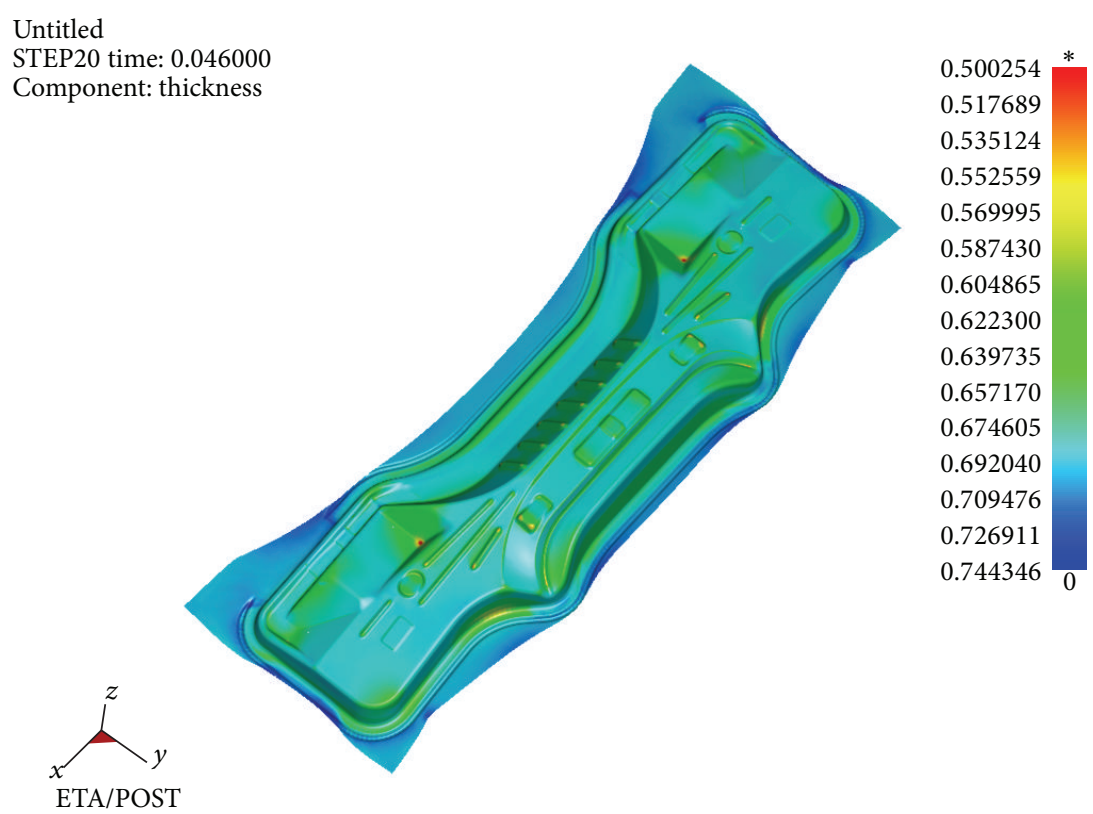

FIGURE 6: Thickness distribution of the forming parts for A1B3C3D1 optimized scheme.

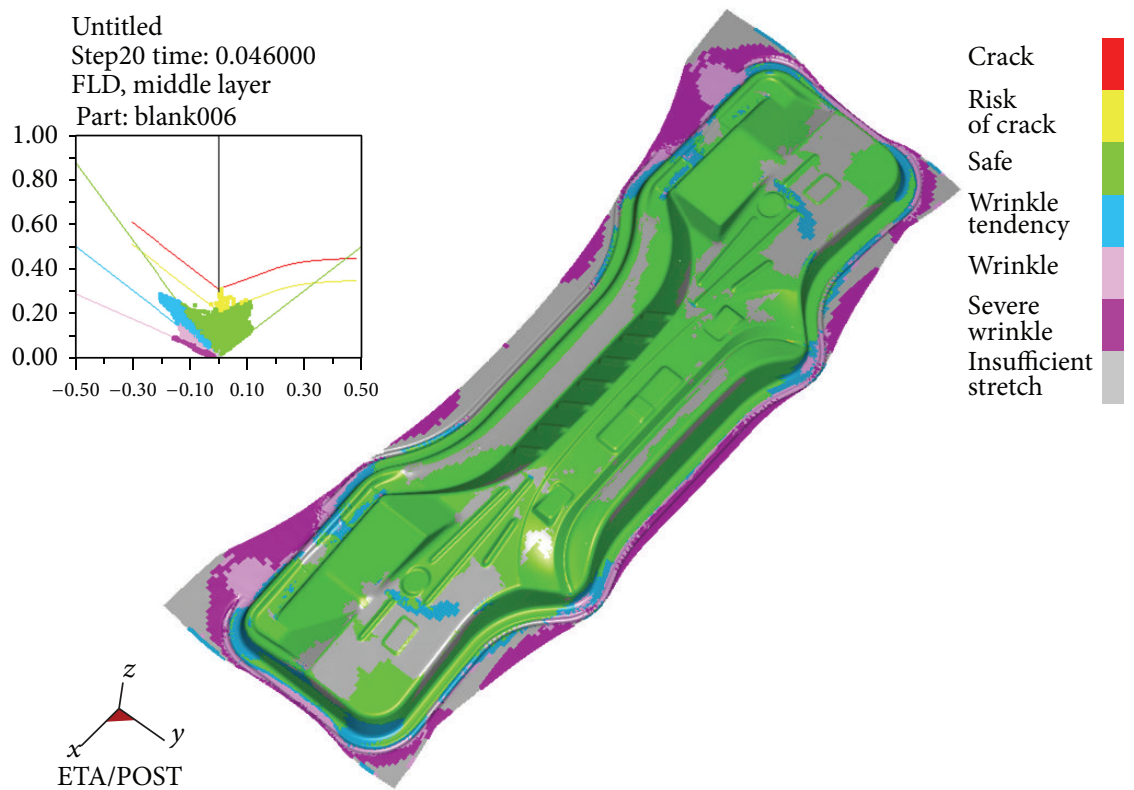

FIgURE 7: Forming limit diagram of the forming parts for A1B3C3D1 optimized scheme.

\section{Conclusions}

In order to study the influence of several process parameters which have great influence on the forming quality on the quality of automotive panels, this paper adopted automotive lower floor board as the research object, selected the BHF, die corner radius, die clearance, and friction coefficient with maximum thinning rate and maximum thickening rate as evaluation indexes, used orthogonal experiment method for simulation analysis on the effects of these four parameters, and carried on optimization. It can be obtained from the experiment that the impact of the four process parameters on the maximum thinning rate from strong to weak is die clearance, friction coefficient, the BHF, and die clearance, while on the maximum thickening, the greatest impact is BHF, followed by the friction coefficient and die clearance and die clearance has little effect. The maximum thinning rate and maximum thickening rate could be effectively controlled through orthogonal experiment optimization, and the high quality forming parts can be obtained without 


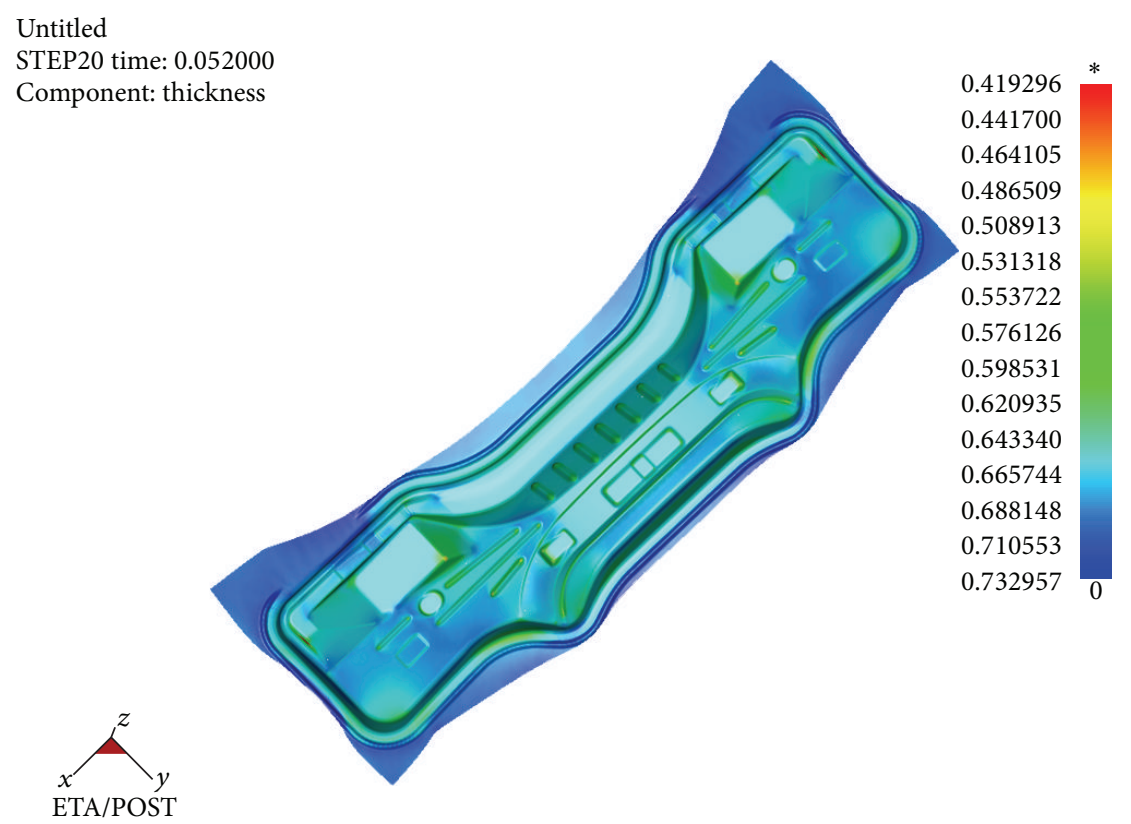

FIGURE 8: Thickness distribution of the forming parts for A3B1C1D3 optimized scheme.

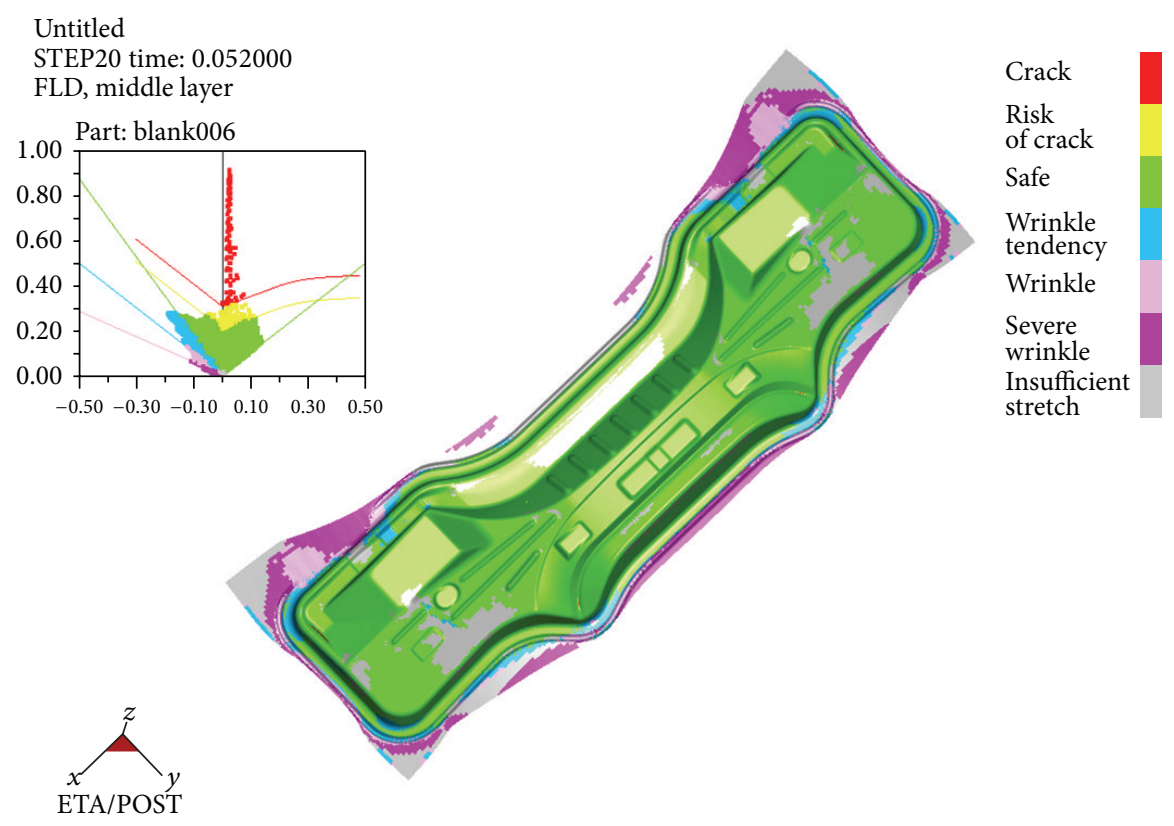

FIGURE 9: Forming limit diagram of the forming parts for A3B1C1D3 optimized scheme.

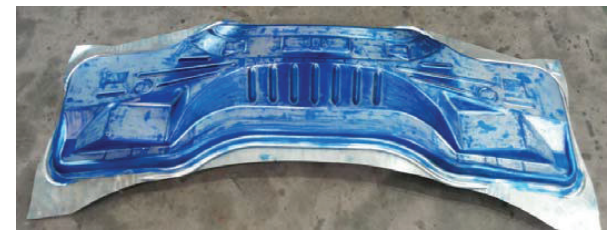

FIGURE 10: Stamping forming part of automotive lower floor board.

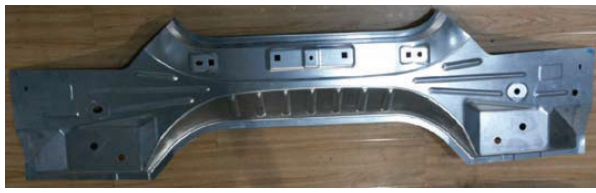

FIGURE 11: The final product part of automotive lower floor board. 
obvious defects. This paper can also verify the feasibility of ETA/Dynaform simulation software in the mold manufacturing and debugging stage for actual production guidance.

\section{Conflict of Interests}

The authors declare that they do not have any commercial or associative interest that represents a conflict of interests in connection with the work submitted.

\section{Acknowledgments}

This work was supported by the Innovation Foundation for Graduate Students of Shandong University of Science \& Technology (Grant nos. YC140105 and YC140205). The authors express sincere thanks to the reviewers for their helpful comments and suggestions for improving this paper.

\section{References}

[1] M. Cavazzuti, A. Baldini, E. Bertocchi, D. Costi, E. Torricelli, and P. Moruzzi, "High performance automotive chassis design: a topology optimization based approach," Structural and Multidisciplinary Optimization, vol. 44, no. 1, pp. 45-56, 2011.

[2] F. Bi, S. J. Hu, and B. Song, "Application of non-Gaussian closure method in automotive chassis non-linear vibration analysis," Forschung im Ingenieurwesen, vol. 75, no. 3, pp. 153-163, 2011.

[3] N.-M. Wang and B. Budiansky, "Analysis of sheet metal stamping by a finite element method," Journal of Applied Mechanics, vol. 45 , no. 1, pp. 73-82, 1978.

[4] N. Wang and S. Tang, "Analysis of bending effects in sheet forming operation," International Journal for Numerical Methods in Engineering, vol. 25, no. 1, pp. 253-267, 1988.

[5] M. Kawka, T. Kakita, and A. Makinouchi, "Simulation of multistep sheet metal forming processes by a static explicit FEM code," Journal of Materials Processing Technology, vol. 80-81, pp. 54-59, 1998.

[6] J. Mackerle, "Finite element analyses and simulations of sheet metal forming processes," Engineering Computations, vol. 21, no. 8, pp. 891-940, 2004.

[7] Y. Wen, W. Zhong, and Y. Liu, "Optimization design of process parameters in sheet metal drawing," Journal of Plasticity Engineering, vol. 20, no. 3, pp. 31-36, 2013.

[8] J. Pan, Y. Zhong, and C. Yuan, "Process parameters optimization for sheet metal forming during drawing with a multi-objective genetic algorithm," Journal of Tsinghua University, vol. 47, no. 8, pp. 1267-1269, 2007.

[9] E. Gao, H. Li, H. Kou, H. Chang, J. Li, and L. Zhou, "Influences of material parameters on deep drawing of thin-walled hemispheric surface part," Transactions of Nonferrous Metals Society of China, vol. 19, no. 2, pp. 433-437, 2009.

[10] W. Liu and Y. Yang, "Study on process optimization and objective functions of sheet metal forming based on FEA," Material Science and Technology, vol. 14, no. 2, pp. 159-161, 2006 (Chinese).

[11] W. Chen, Sheet Metal Forming CAE Analysis Tutorial, China Machine Press, Beijing, China, 2005, (Chinese).

[12] F. Barlat and J. Lian, "Plastic behavior and stretchability of sheet metals. Part I: a yield function for orthotropic sheets under plane stress conditions," International Journal of Plasticity, vol. 5, no. 1, pp. 51-66, 1989.

[13] D. Ko, S. Cha, S. Lee, C. Lee, and B. Kim, "Application of a feasible formability diagram for the effective design in stamping processes of automotive panels," Materials and Design, vol. 31, no. 3, pp. 1262-1275, 2010.

[14] M. Firat, O. H. Mete, U. Kocabicak, and M. Ozsoy, "Stamping process design using FEA in conjunction with orthogonal regression," Finite Elements in Analysis and Design, vol. 46, no. 11, pp. 992-1000, 2010.

[15] K. Park and Y. Kim, "The effect of material and process variables on the stamping formability of sheet materials," Journal of Materials Processing Technology, vol. 51, no. 1-4, pp. 64-78, 1995.

[16] L. Chen, W. Chen, J. D. Li, S. N. Heng, and J. Wu, "Optimal design about parameters of cooling pipes in hot stamping die," Advanced Materials Research, vol. 988, pp. 263-267, 2014.

[17] S. Wu, Sheet Metal Forming Technology and Mold Design, Northwestern Polytechnical University Press, Xian, China, 2002 (Chinese).

[18] K. Chung, K. Hyunki, and C. Lee, "Forming limit criterion for ductile anisotropic sheets as a material property and its deformation path insensitivity. Part I: deformation path insensitive formula based on theoretical models," International Journal of Plasticity, vol. 58, no. 7, pp. 3-34, 2014. 


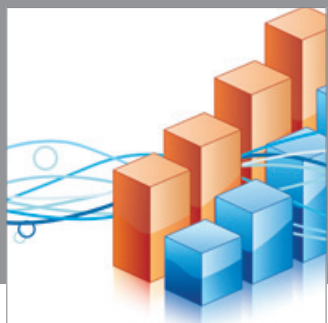

Advances in

Operations Research

mansans

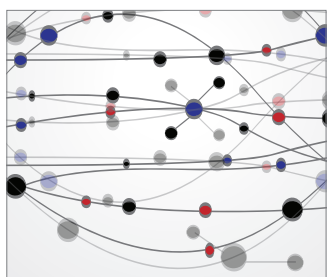

The Scientific World Journal
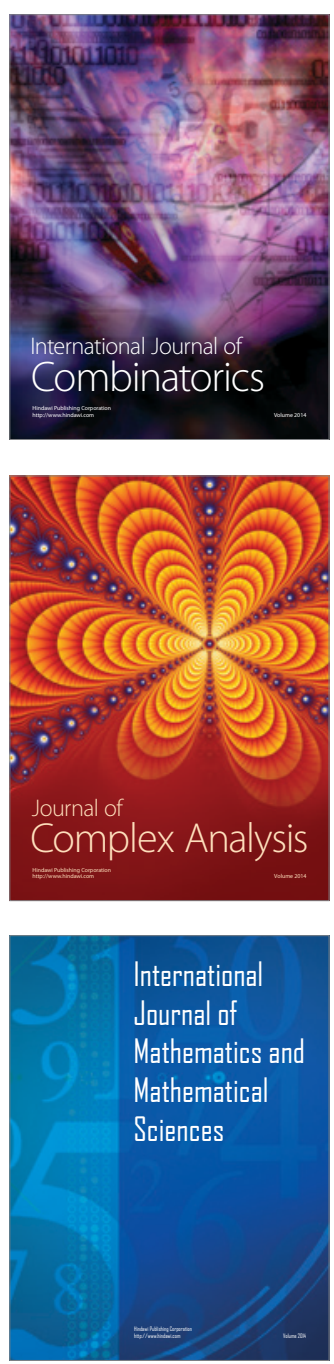
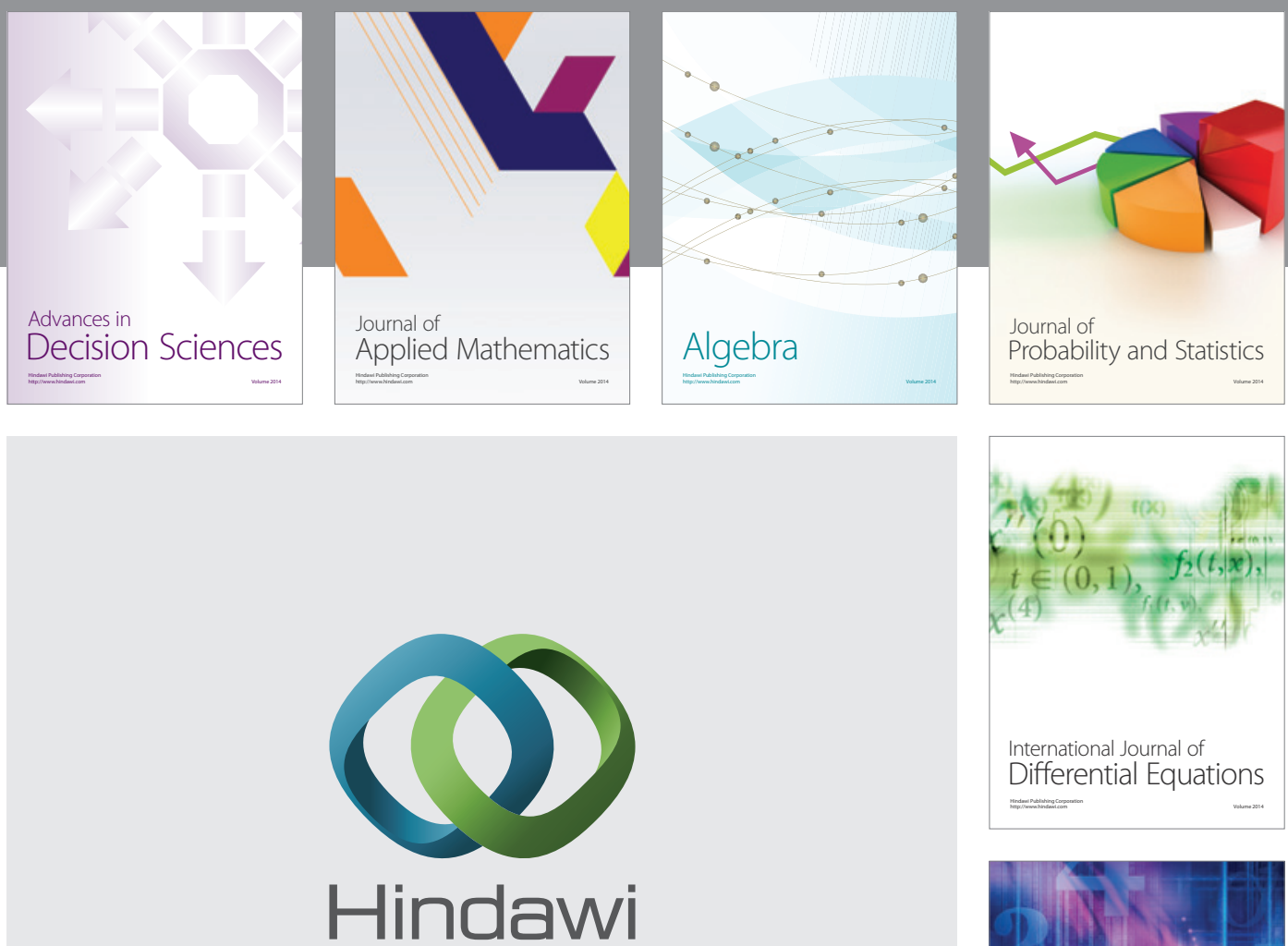

Submit your manuscripts at http://www.hindawi.com
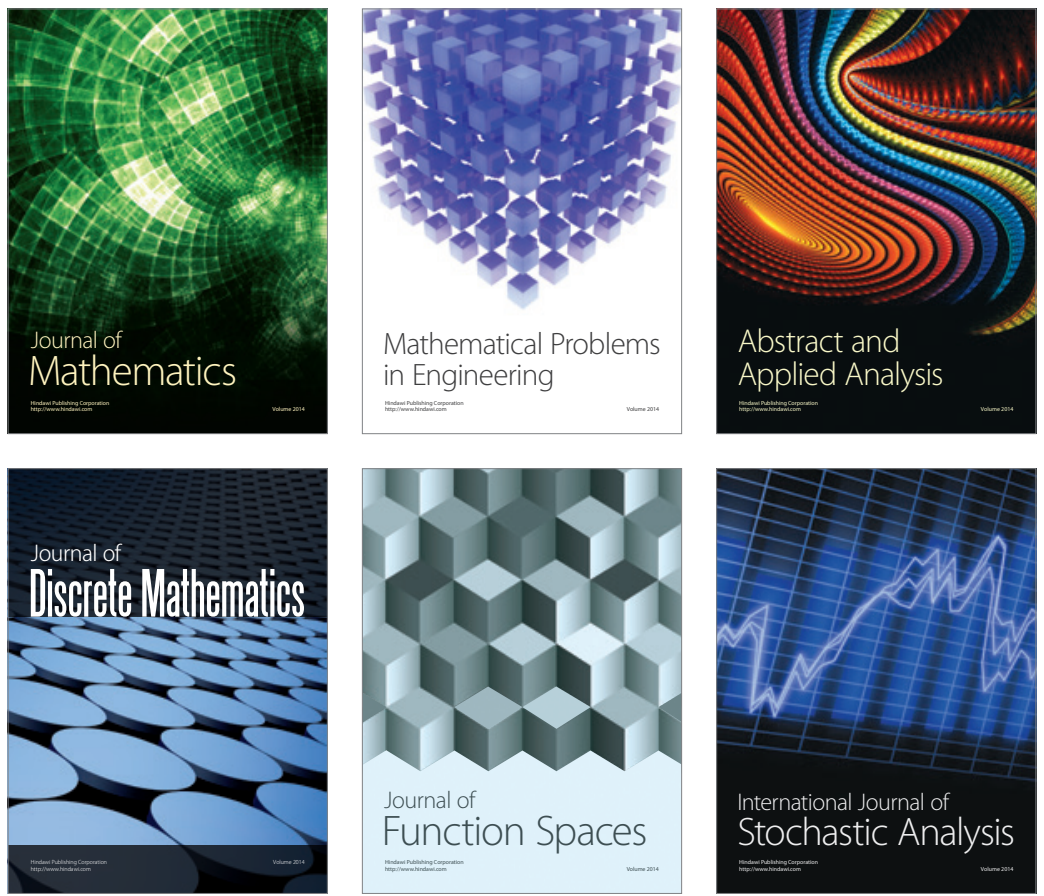

Journal of

Function Spaces

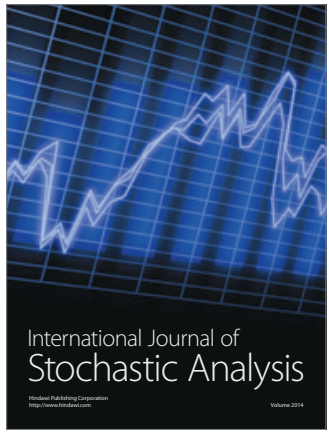

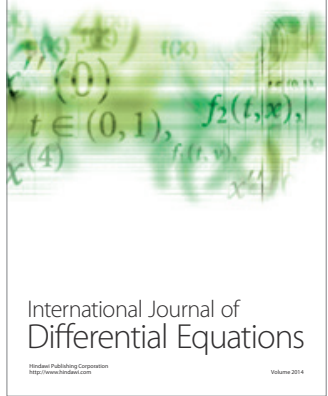
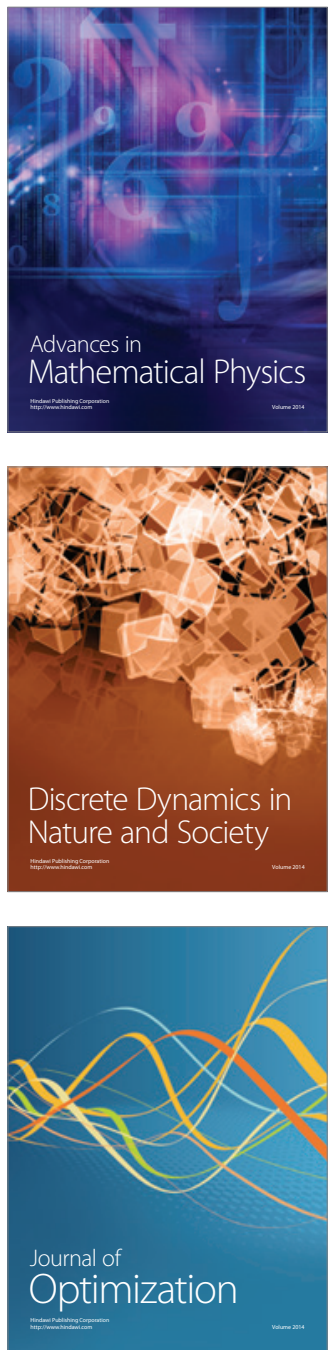